\title{
Democratización de la pobreza en Chiapas
}

Poverty's democratization in Chiapas

\author{
Jorge López Arévalo* \\ Gerardo Núñez Medina**
}

\section{Resumen}

Desde que iniciaron las mediciones de pobreza en México, Chiapas ha ocupado siempre uno de los primeros lugares a nivel nacional en la proporción de población que vive bajo condiciones de pobreza patrimonial y alimentaria. El porcentaje de población que vivía en pobreza patrimonial en Chiapas alcanzó 75.1\% en el año 1990, veinte años después la cifra llegó a $78.1 \%$. Estos resultados muestran, por una parte, el fracaso de los programas de combate a la pobreza, mientras que por otra parte, son producto de una combinación de la falta de dinamismo de su economía y el rápido incremento de la población, todo ello exacerbado por los altos niveles de desigualdad social y económica, además de factores de carácter discriminatorio de facto hacia las poblaciones indígenas.

Entre los años 1990-2010, los niveles de pobreza alimentaria crecieron de forma más dramática en los municipios con mayores niveles de marginación, es decir, en 87 de los 118 municipios, por lo que la pobreza alimentaria cubrió poco más de tres cuartas partes del territorio del estado con niveles superiores a 50\%. Lo que implica que la pobreza se ha democratizado no solo entre los individuos sino también entre los municipios y que abarca cada día una mayor proporción del territorio chiapaneco.

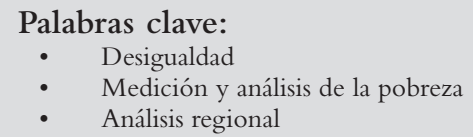

Abstract "

Since measures of poverty began in Mexico, Chiapas has always been one of the top at national level in the proportion of population living under patrimony and food poverty conditions. The percentage of population living in patrimony poverty in Chiapas reached $75.1 \%$ in 1990 , twenty years later the figure reached $78.1 \%$. These results show, first, the failure of combat poverty programs, while on the other hand, are product of a combination of lack of economic dynamism and the rapid population growth, all exacerbated by high levels of social and economic inequality, besides discriminatory factors towards indigenous populations.

Between 1990 and 2010, food poverty levels increased more dramatically in municipalities with higher levels of marginalization, it means 87 of 118 municipalities, so food poverty covered three quarters of state territory with levels over 50\%. This imply that poverty has democratized not only between people but also between municipalities and each day covers a greater proportion of Chiapas.

JEL: D63, I32, O18

\section{Introducción}

El desplome continuado del producto interno bruto (PIB) de Chiapas a partir del año 1980 hasta la fecha, producto de la aplicación de una política económica neoliberal que entre otras consecuencias ha traído el desmantelamiento de la actividad productiva del campo, principal fuente de empleo de los chiapanecos,

*Profesor de economía en la Facultad de Ciencias Sociales, Universidad Autónoma de Chiapas 
a la par del crecimiento de la población, con tasa sostenida por arriba de 3\% anual, una de las más altas de todo México, cuyas consecuencias han sido, el crecimiento de los ejércitos laborales de reserva, en especial mano de obra no calificada.

Si bien el desplome de la economía junto con el rápido incremento de la población derivó, por obvias razones, en un incremento del número de personas en condición de pobreza, existen además ingredientes que exacerbaron dicha condición, tales como los altos niveles de desigualdad en factores tan importantes como el acceso a los servicios de salud, educación y mercados laborales. Además de un importante factor discriminatorio hacia las poblaciones indígenas que presentan, en general, el doble de los niveles de pobreza que los observados en poblaciones mestizas.

En un primer momento, los programas sociales de combate a la pobreza tenían por objeto eliminar la pobreza en México, no obstante, ya para el año 2010, el objetivo de los programas había cambiado a eliminar la transmisión intergeneracional de la misma. La reducción de expectativas de los programas de combate a la pobreza va de la mano con la falta de resultados observados por parte de los mismos. Lo cual se hace evidente con solo seguir el número de personas en condición de pobreza, tanto a nivel nacional como en Chiapas. El fracaso de los programas de combate a la pobreza, en el caso de Chiapas, ha traído además del incremento en el número de pobres, una democratización de la pobreza la cual alcanza niveles que van de 13 a $86 \%$ de personas en pobreza alimentaria en todas las localidades del estado al año 2012 según cifras del Consejo Nacional de Evaluación para la Política de Desarrollo Social (CONEVAL). Además, poco más de la mitad de las localidades presentan niveles de pobreza alimentaria superiores a 50 por ciento.

Si bien, la pobreza no surge únicamente como resultado de la mala aplicación de políticas públicas, sino que tiene profundas raíces estructurales, que determinan la falta de acceso a la educación y posteriormente a un empleo formal, con un salario digno, lo que permite a las personas hacerse de los benefactores mínimos para escapar de la pobreza. Dichos elementos han contribuido en la entidad a agudizar y perpetuar las condiciones de pobreza, en especial entre las poblaciones rurales (geográficamente más aisladas) y las poblaciones indígenas, donde los niveles de pobreza y marginación son mucho más altos que los de poblaciones urbanas o mestizas. En general, se puede hablar de una democratización de la pobreza en una sociedad donde tres de cada cuatro personas $(74.7 \%)$ se encuentra en condiciones de pobreza, $42.5 \%$ 
en pobreza moderada y $32.2 \%$ en condición de pobreza extrema, tal y como lo reporta CONEvAL al año 2012 para Chiapas.

\section{Chiapas, estructura económica y pobreza}

La pobreza ha marcado la vida de muchas generaciones de Chiapanecos. Desde hace más de un siglo la economía de Chiapas ha mostrado tasas de crecimiento económico mediocres, muy por debajo de la media nacional, excepto para el periodo 1970-1980 (Peláez y López, 2013). ${ }^{1}$ Lo que aunado a los problemas de desigualdad en la repartición de la riqueza ha tenido como resultado los niveles de pobreza más altos de todo el país, lo que evidencia importantes fallas en la estructura económica del Estado. En términos relativos, la menor distancia del PIB per cápita de Chiapas con respecto al nacional se observó en el año de 1980. Sin embargo, aun en los años de mayor prosperidad, la riqueza promedio de los chiapanecos llegó a representar apenas dos tercios del resto del promedio de los demás habitantes del país. El año de mayor distancia fue 1960 cuando el producto por habitante de Chiapas llegó únicamente a 37\% del resto de México. En 1900 el PIB por habitante de Chiapas había sido de 63.1\% y sólo se vino a superar en 1980. Se necesitaron 80 años para que el promedio inicial del cual había partido en 1900 se superara (ver gráfica 1).

\footnotetext{
${ }^{1}$ Es importante aclarar que hay un sesgo en 1980 por el petróleo que generaba más de 44\% del PIB de Chiapas y la entidad ocupó el segundo lugar nacional en la producción petrolera, solo después de Tabasco. Campeche aun no era importante productor de petróleo y su producción se computaba como aguas territoriales. Si quitamos el petróleo en 1980, Chiapas ocupa el lugar 16 en PIB y el 30 en PIB per cápita. Si las aguas territoriales se imputan a Campeche, que así era básicamente, sin petróleo, Chiapas sube al lugar 29 en PIB per cápita sin petróleo. En cualquier caso Chiapas no era el último con petróleo y sin petróleo en el PIB per cápita.
} 


\section{Gráfica I}

Producto Interno Bruto per cápita de Chiapas con respecto al resto de México con base a valores de pesos de 2003 (\%)

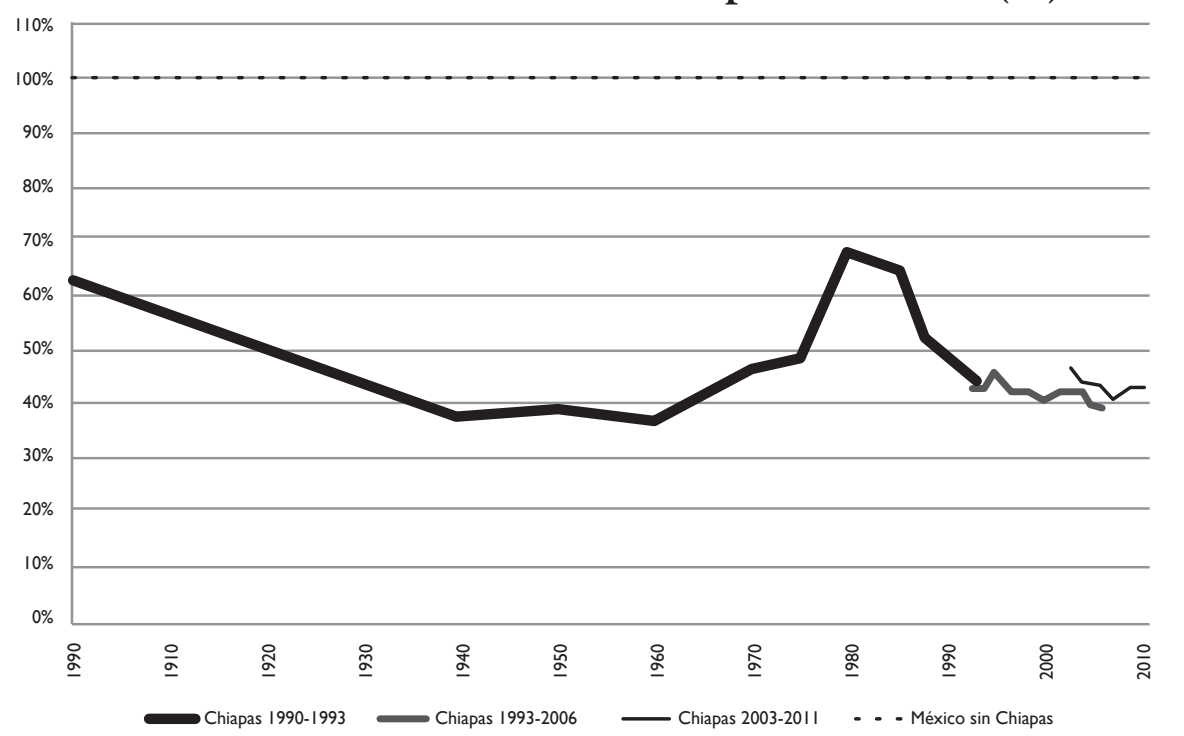

Fuente: elaboración Peláez, 2013.

La gráfica 1 proporciona información sobre el crecimiento económico que registró Chiapas en el periodo 1960-1980, periodo en el cual el PIB per cápita se triplicó, mientras que en el resto del país ni siquiera se duplicó (época del modelo de Industrialización Sustitutiva de Importaciones). Lo contrario ocurrió en las últimas dos décadas del siglo xx y principios del siglo xxI, a partir de la implementación del modelo neoliberal, lo que provocó que en 2013 el PIB per cápita de Chiapas apenas representase 40.2\% del nacional (cálculos en base a INEGI y Conapo).

En relación al crecimiento económico existe una polémica entre quienes son afines a los planteamientos neoclásicos, pues sostienen que las regiones de menor desarrollo deben de crecer más rápido que las más avanzadas, argumentando que, a largo plazo, el funcionamiento del mercado lleva a que las regiones más atrasadas crezcan más rápido (Borts y Stein, 1964). Se trata, de una visión "optimista" del desarrollo, según la cual la intervención no es necesaria, ya que el crecimiento de las regiones rezagadas está garantizada, pudiendo darse a un ritmo incluso superior al que en su momento mostraron 
las regiones ahora destacadas, ya que las seguidoras, por ejemplo, no tienen que soportar costos de innovación (Peláez y López, 2013). ${ }^{2}$

\section{Gráfica 2}

Población de Chiapas 1895-2015

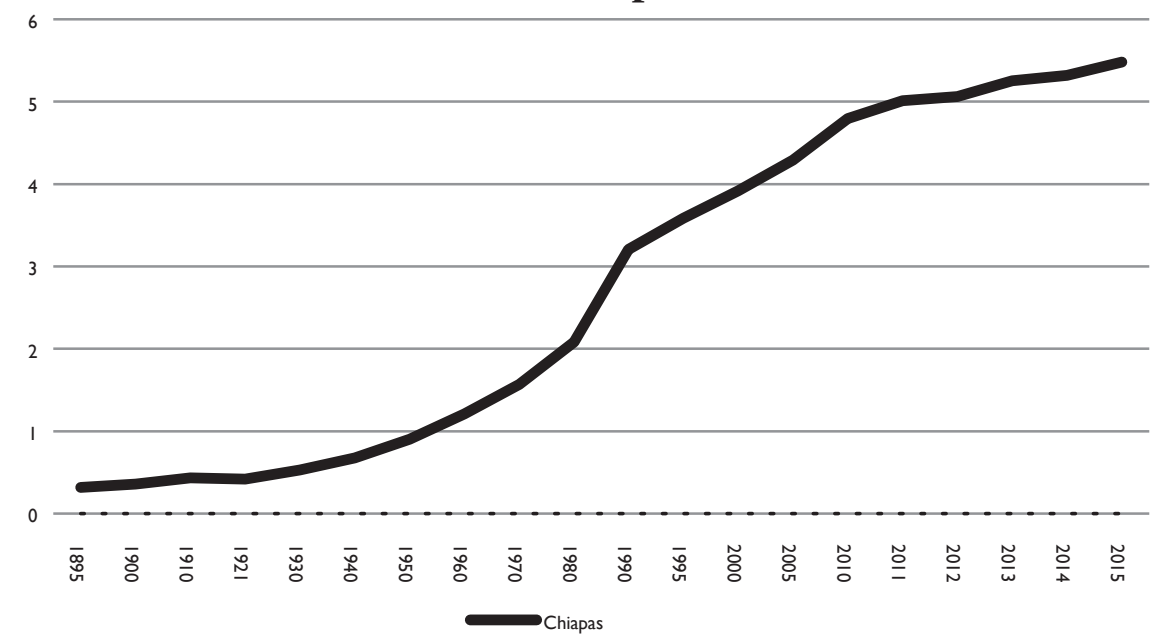

Fuente: estadísticas históricas INEGI y estimaciones propias.

Las regiones ricas entran en una "espiral virtuosa" que las lleva a ser cada vez más ricas, al tiempo que las pobres quedan atrapadas en un "círculo vicioso" que impide su mejora, dando lugar a un proceso de divergencia del que sólo se puede escapar mediante la aplicación de políticas específicas, que tengan como finalidad incentivar el desarrollo económico. Es por ello que algunos autores, como Sachs (2005) o Collier (2007), hablan de la "trampa de la pobreza".

En relación a México, se observa que para todo el periodo (1900-2012) las disparidades no se redujeron y no se tienen evidencias que los estados más pobres tiendan a crecer más rápido que los comparativamente más ricos, ni que haya disminuido la dispersión de manera sostenida. Es decir, la convergencia económica entre entidades federativas no ha sido una constante a lo largo del tiempo sino más bien una excepción (Peláez y López, 2013). La misma analogía puede hacerse para los distintos municipios del Estado de Chiapas, donde

${ }^{2}$ Desde esta perspectiva, la asimilación de la tecnología de los líderes garantiza el crecimiento acelerado de los seguidores. Si bien en el campo de la economía este argumento puede enfrentar ciertas restricciones, como la existencia de competencia imperfecta o de economías de escala, el mismo, resulta incuestionable en otros ámbitos y con otras variables, como la esperanza de vida (Guijarro y Peláez, 2008, Peláez, 2009, Peláez, Guijarro y Arias, 2010). 
la convergencia parece estar ocurriendo pero en sentido contrario, es decir, hacia una homogenización de los niveles de pobreza entre municipios.

La política neoliberal fue implementada en México como única alternativa para salir airosos de los retos originados por el proceso de globalización y para retomar la senda del crecimiento económico sostenido. Sin embargo, dicha política, en lugar de corregir las distorsiones de la economía y alcanzar una inserción exitosa en el contexto internacional, profundizó los desequilibrios productivos, lo que desembocó en las crisis de fines de 1994-1995, 20012002, 2008-2009. Esta situación cambió el perfil de la economía mexicana, pues pasó de privilegiar una política de ampliación del mercado interno a una exógena que priorizar el externo. En este punto está la esencia del cambio de modelo y ha tenido implicaciones diferentes para las regiones; en especial para el estado de Chiapas, donde el cambio de modelo terminó por desmantelar la estructura productiva y agudizar la ya endémica situación de pobreza de la población.

\section{Gráfica 3}

\section{Características del mercado de trabajo en Chiapas 2005-2 ${ }^{\circ}$ semestre de 2013 (personas)}

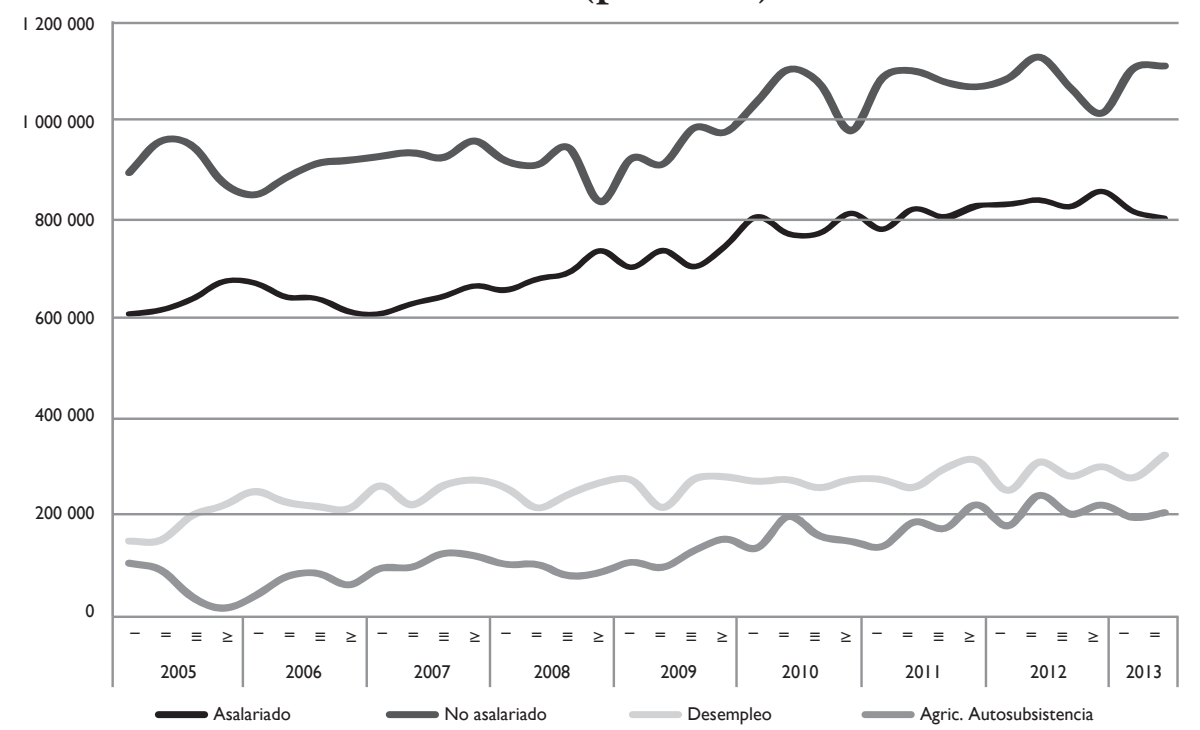

Fuente: elaboración propia con base en datos de la ENOE.

El cambio de modelo económico provocó un descenso del PIB per cápita, en Chiapas, lo cual profundizó problemas estructurales, tales como el incremento 
de los niveles de desempleo, mismos que intentaron ser paleados a través de políticas asistencialistas dirigidas desde el ejecutivo federal y que aterrizaron en programas sociales tales como: Solidaridad, Progresa, Oportunidades y Prospera.

\section{Grafica 4}

Trabajo asalariado por sector $(\%)$

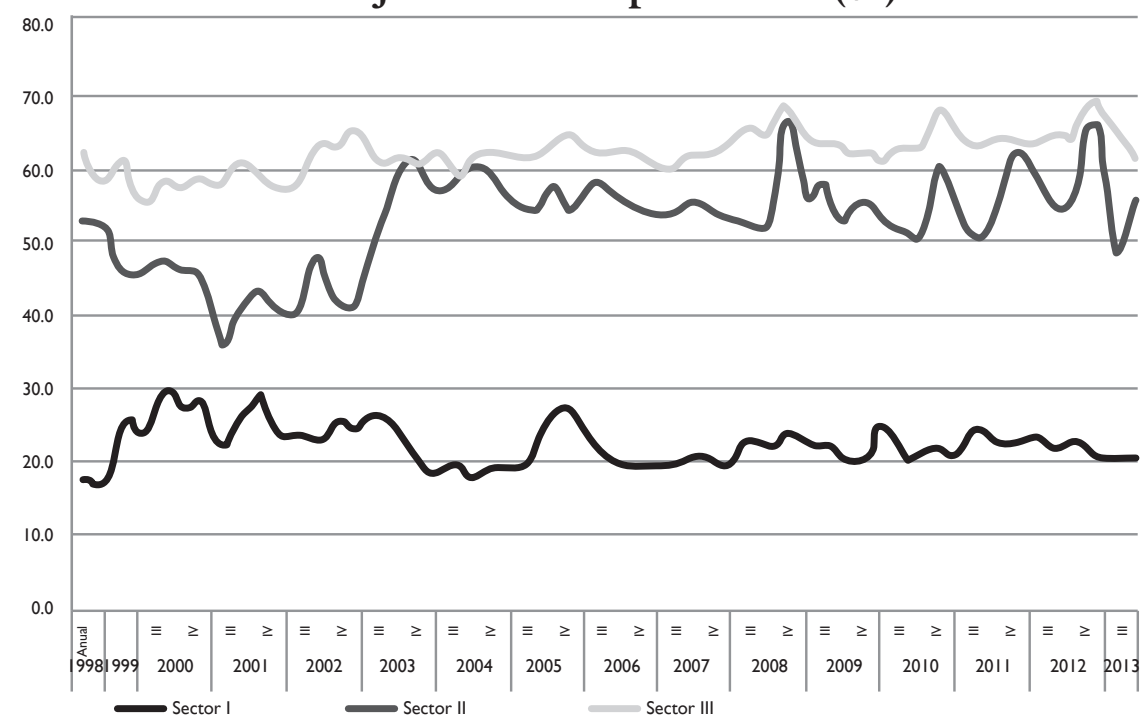

Fuente: elaboración propia con base en datos de la ENOE.

El comportamiento de la dinámica económica a partir de 1980, en Chiapas, no ha podido responder a la presión que ejerce la población económicamente activa sobre un mercado de trabajo débilmente estructurado. La población del Estado se duplicó en un plazo de veinte años. Paso de dos millones de habitantes en 1980 a cuatro millones en el año 2000 y se prevé que alcance los 5.4 millones en el año 2015. Véase gráfica 2. En el 2012, el empleo formal en el país es proporcionalmente tres veces superior al de Chiapas; la tasa de trabajo asalariado a nivel nacional era de casi $62.5 \%$ mientras que en Chiapas de 43.9\%; la tasa de condiciones críticas de ocupación de la entidad es tres veces mayor a la nacional y el índice de polarización económica de Chiapas es del doble respecto al nacional; en contra parte, la tasa de desempleo abierto del inEGi (es un indicador que debe leerse al revés en economías donde impera el rezago social), en Chiapas exhibe los niveles más bajos del país, lo que 
ocurre porque el desempleo es una variable relacionada con la flexibilidad o la rigidez, eficiencia o ineficiencia de los mercados laborales.

Cuadro I

Trabajo asalariado según sector $(\%)$

\begin{tabular}{lll|l}
\multicolumn{1}{c|}{ Sectores } & 2000 & 2006 & 2012 \\
Gobierno & 99.6 & 98.4 & 98.9 \\
Industria extractiva & 99.8 & 98.2 & 89.9 \\
Servicios sociales & 96.9 & 93.1 & 94.6 \\
Transporte & 75.4 & 79.9 & 83.0 \\
Servicios diversos & 57.5 & 75.1 & 76.9 \\
Servicios profesionales & 56.5 & 64.2 & 75.3 \\
Construcción & 72.7 & 74.0 & 71.5 \\
Manufacturas & 29.9 & 38.6 & 44.7 \\
Restaurantes & 35.3 & 39.2 & 44.0 \\
Comercio & 38.2 & 35.7 & 39.2 \\
Agricultura & 26.5 & 22.6 & 22.2 \\
\hline Fuente: elaboración propia con base en ENOE. & & \\
\hline
\end{tabular}

Identificar el desempleo abierto con la marginación es un error conceptual, ya que un desempleado mantiene las expectativas de vincularse al mercado de trabajo y el marginado carece de expectativas para probar suerte en el mercado laboral (Nájera y López, 2012). En Chiapas, la población no económicamente activa que muestra disponibilidad de incorporarse al mercado de trabajo es de alrededor de $12.7 \%$ y la agricultura de autosubsistencia representa $11.2 \%$ de la población ocupada, mientras a nivel nacional es de 3.8\% (Datos de ENOE).

Las gráficas 3 y 4 muestran la composición del mercado de trabajo en Chiapas, el trabajo no asalariado es dominante en la economía de la entidad, el desempleo es considerablemente alto (calculado a partir de la metodología del Centro de Análisis Multidisciplinario de la Facultad de Economía, UnAM o de la Organización Internacional del Trabajo). En términos sectoriales, si consideramos la tasa de trabajo asalariado como un indicador del grado de desarrollo del capitalismo, el sector terciario presenta el mayor grado de penetración en Chiapas, seguido del secundario y la agricultura.

$\mathrm{Si}$ desagregamos por sectores, encontramos que el gobierno en Chiapas es la institución que emplea "relativamente" más personal asalariado y le sigue la industria extractiva (minería, incluye petróleo). Sin embargo, podemos ver que 
dos sectores de la actividad económica que son típicamente transables, industria manufacturera y agricultura, son mayoritariamente, no capitalistas. Es decir, en los sectores no transables es donde hay mayor penetración de la relación social capitalista que se expresa en mayor trabajo asalariado, mientras que en las transables ocurre lo contrario.

\section{Gráfica 5}

Índice de desigualdad de Gini, México y Chiapas 1990, 2000 y 2010

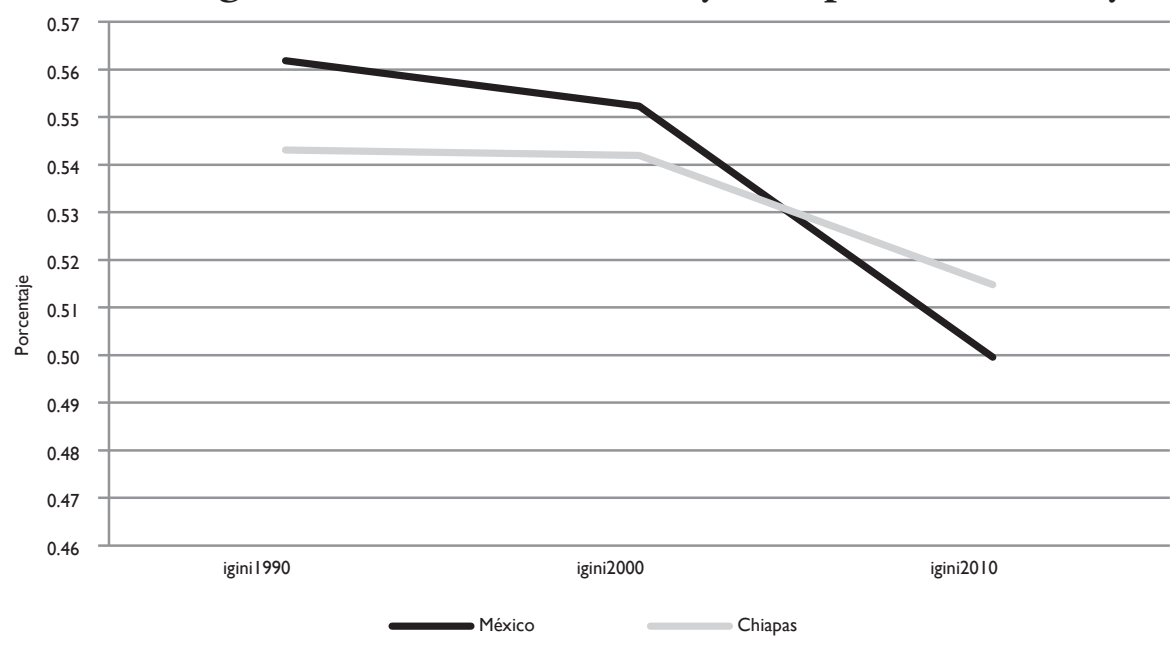

Fuente: elaboración propia con datos de CONEVAL.

Dada la baja capacidad para generar empleo en la entidad se puede decir que existe abundante oferta de mano de obra, pero de baja calificación, en Chiapas y que la demanda no crece en la misma proporción por la falta de dinamismo de la economía, por eso se refugia en actividades de baja productividad, en la informalidad y el subempleo. Se estima que la población desempleada es de 85179 chiapanecos (Cálculos a partir de ENOE). Este viene a ser un dato estructural que amén de agravar el desempleo y la marginalidad (Valenzuela, 2013), aumenta la precariedad laboral y los bajos salarios. En este sentido, la pobreza que sufre la población que aun teniendo un empleo no puede adquirir la canasta alimentaria con su ingreso laboral se mide a través del índice de la tendencia laboral de la pobreza, el cual se ha mantenido especialmente alto en el estado, tal y como se muestra en la gráfica 6.

Como se ha señala, el sector rural de Chiapas muestra un serio estancamiento que genera un excedente importante de mano de obra, cuyas opciones son sombrías: a) el capitalismo urbano en Chiapas es débil o inexistente. En 
general, su capacidad de absorción ocupacional es nula (cuadro 1); b) el capitalismo nacional, el vigente en las regiones medias y más adelantadas del país. Pero este sector, tampoco es capaz de dar empleo en cantidades importantes. De hecho, es expulsor neto (Valenzuela, 2013). Nos encontramos, en consecuencia, con una masa potencial de migrantes sin destino, o con una población sujeta a la subsistencia a partir de los subsidios entregados vía programas de desarrollo social.

\section{Gráfica 6}

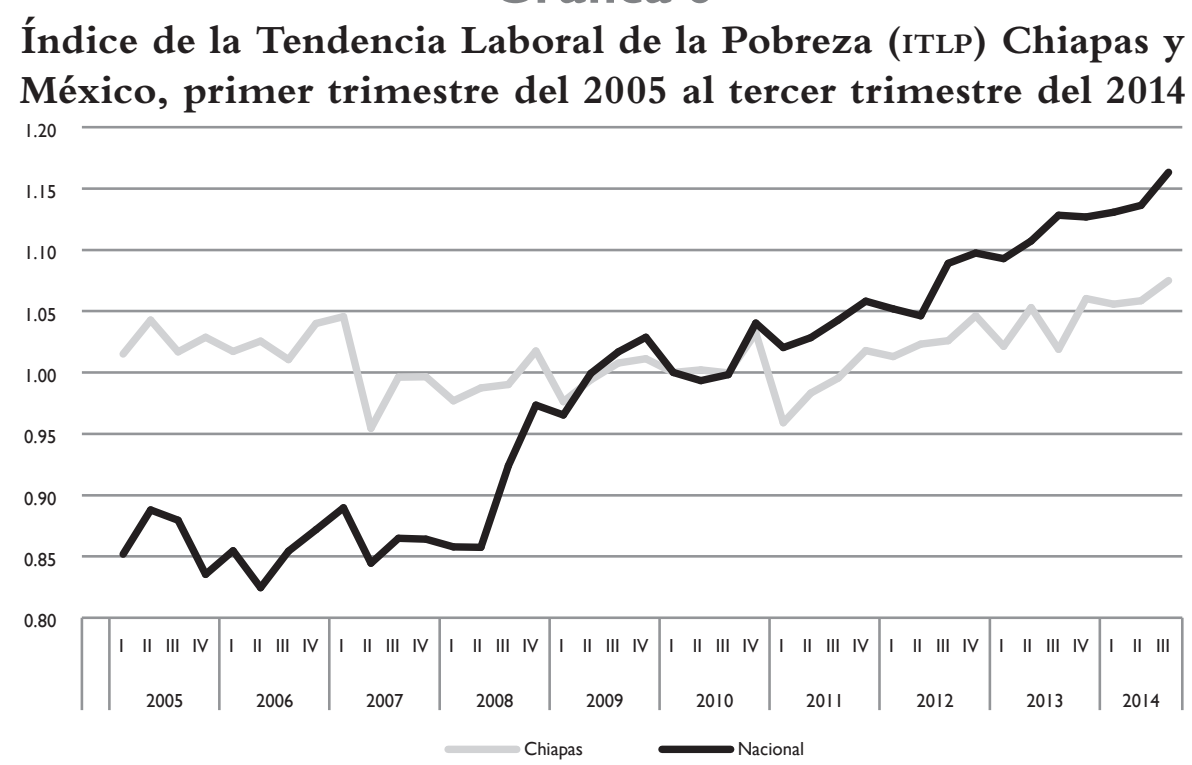

Fuente: elaboración propia con base en datos de CONEVAL.

A saber, la fuerza de trabajo redundante busca refugio en: i) migrando a EEUU $;{ }^{3}$ ii) incorporándose a las filas de la informalidad o, refugiándose en la

\footnotetext{
${ }^{3}$ Examinando el caso de la sierra de Chiapas, se ha señalado que antes de la crisis en EEUU, "de la localidad de Motozintla salían semanalmente hasta tres autobuses con migrantes rumbo a la frontera, es decir, un promedio de 130 migrantes por semana, más de 500 por mes y poco más de 6 mil por año, cifra que equivale a 3.7\% de la población actual de la zona." Cf. (Villafuerte, 2010). El 66\% de los desplazamientos de migrantes chiapanecos hacia Estados Unidos tiene entre 15 y 29 años de edad. En trabajo de campo en la Sierra, en la Costa y en el Soconusco se han encontrado evidencias que nos indican que los jóvenes alimentan los circuitos migratorios de chiapanecos a Estados Unidos y la edad promedio es de 25.97 años. (Escobar, Sovilla y López, 2006). Si la comparación se hiciera con el cohorte de la PEA adecuado (vg. entre 15 y 40 años), de seguro el porciento de migrantes subiría a alrededor de un 10 a 15\% (Valenzuela, 2013).
} 
agricultura de autosubsistencia; iii) incorporándose a actividades ilícitas: narcotráfico y otras ${ }^{4}$ (Valenzuela, 2013).

El excedente de mano de obra, de Chiapas, resulta estar formado por una población joven, con bajos niveles de capacitación, rural y con un componente indígena importante. No cuenta con opciones reales de desarrollo, dada su condición, por lo que resulta presa fácil del clientelismo político. Las opciones que tiene de encontrar empleo decente son casi inexistentes, así que se refugia en el subempleo, la informalidad, la emigración, las disputas por recursos en dónde puede obtener alguna renta (bancos de grava, sitios turísticos, pozos de agua, casetas de cobro en carreteras, etcétera). El abandono, la pulverización de la propiedad agrícola, el fin de la frontera agrícola y falta de tecnificación del campo, que por muchos años fue su fuente principal de empleo, se ha convertido en inviable en un contexto de agricultura de fronteras abiertas.

La combinación de las cifras desempleo y subempleo aunado a los bajos niveles salariales, en la entidad, han traído como consecuencia una fuerte contracción del gasto corriente de las familias. El resultado final es que los niveles de pobreza en el estado parecen no disminuir en el tiempo, a pesar de las inversiones millonarias en gasto social, que tienen 16 años implementándose.

\section{Pobreza y desigualdad en Chiapas}

Chiapas nos sitúa en el peor de los mundos posibles. Su PIB per cápita ha descendido de 1980 a la fecha dramáticamente y la distribución del ingreso es la de mayor desigualdad en el país, tal y como puede verse en la gráfica 5. Por lo anterior, podemos sostener que en Chiapas existe una crisis de carácter estructural, pues no es capaz ni siquiera de garantizar el crecimiento económico, menos de generar riqueza que debería ser la condición sine qua non del capitalismo; además, si consideramos que el grado de legitimidad del capitalismo se lo da la capacidad que tienen su élites para reinvertir el excedente económico que se apropian y así desarrollar las fuerzas productivas (Palma, 2011), con las respectivas políticas redistributivas del ingreso para generar demanda efectiva.

\footnotetext{
${ }^{4}$ Por obvias razones la organización interna de los cárteles de la droga es algo poco conocido. Pero podemos suponer que se acerca a la forma capitalista: operan a gran escala y en diversos países, con personal asalariado al parecer muy bien pagado y con una altísima tasa de ganancia. Muy probablemente, la de la droga es la "rama" de mayor crecimiento en la última década y media. Además, se trata de un poder económico que ya se proyecta como poder político. El secuestro, la extorsión, el robo a servicios e industrias públicas, el tráfico de personas, así como los "prestamistas" usureros, "coyotes", asociados a la migración, parecen ser otras actividades especialmente dinámicas. Todo lo cual, amén de siniestro, nos revela el grado de descomposición, económica y moral, al que ha llegado el sistema (Valenzuela, 2013).
} 
Es por ello, que en Chiapas, la curva de la demanda doméstica no es lineal, debido a lo pronunciado de las desigualdades del ingreso (la mayor parte de la población es pobre), las clases bajas no pueden acceder a los bienes duraderos de importancia (Salama, 2008; 25).

La pobreza va de la mano con la marginación, tanto a nivel de localidad como municipal es claro que a mayor marginación mayor pobreza y viceversa. La gráfica 7 muestra la relación que existe entre los niveles de marginación reportados por el Consejo Nacional de Población y el porcentaje de población que padece pobreza alimentaria a nivel municipal, para el estado de Chiapas al año 2010.

\section{Gráfica 7}

\section{Población en pobreza alimentaria por grado de marginación municipal Chiapas 2010}

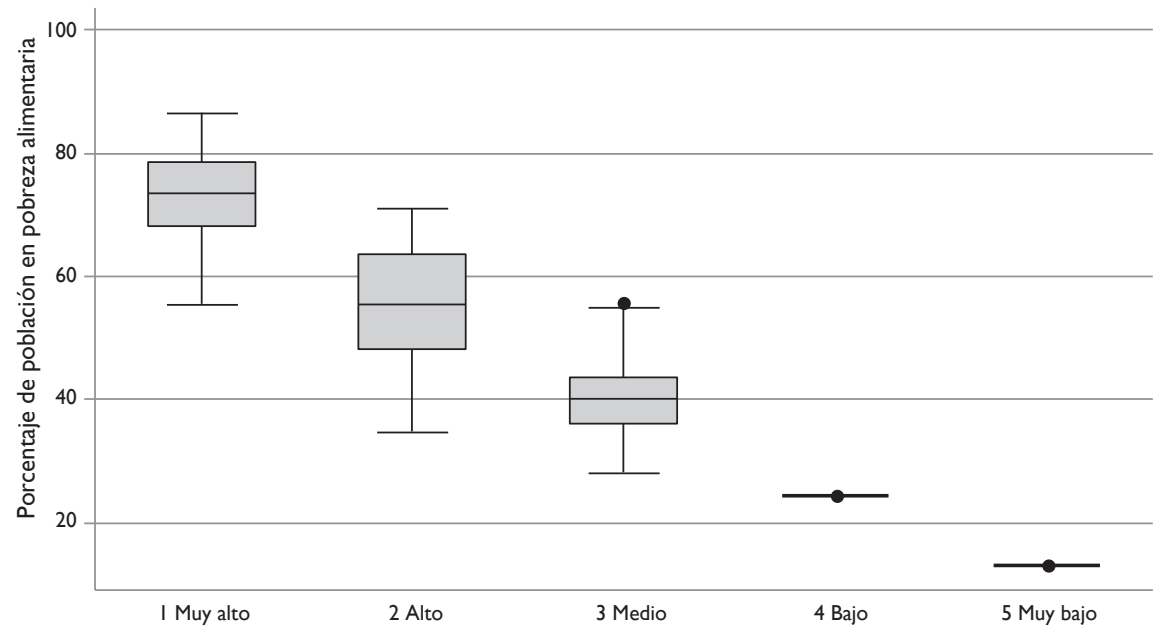

Fuente: elaboración propia con base en datos de CONEVAL.

En el caso de Chiapas, de acuerdo a CONEVAL, en 2012, 3 de cada 4 personas se encuentran en situación pobreza y 1 de cada 2 en pobreza alimentaria. Es decir, sólo las personas que gozan de un nivel de ingresos que escapa de la pobreza, 1 de cada 4 , pueden constituirse en demanda efectiva y puede adquirir bienes de "lujo" en el sentido ricardiano (Salama, 2008). Por su parte, los niveles de pobreza alimentaria reportados para Chiapas resultan ser muy superiores a la media nacional para las tres mediciones presentadas por CONEVAL. Puede observarse claramente que los niveles de pobreza alimentaria y de capacidades de Chiapas están por arriba del doble del promedio nacional y lo que 
parece aún más grave es que la brecha no parece estar cerrándose pese a que Chiapas es el principal destinatario a nivel nacional de los programas sociales.

\section{Cuadro 3}

\section{Evolución de la pobreza en Chiapas y promedio nacional}

\begin{tabular}{c|cccccccccc}
\hline \multicolumn{1}{c|}{ Pobreza por Ingresos } \\
$\begin{array}{c}\text { Entidad } \\
\text { Federativa }\end{array}$ & \multicolumn{3}{c}{ Alimentaria } & \multicolumn{3}{c|}{ Capacidades } & \multicolumn{3}{c}{ Patrimonio } \\
& 1990 & 2010 & Dif. & 1990 & 2010 & Dif. & 1990 & 2010 & Dif. \\
Nacional & 23.7 & 18.8 & -4.9 & 31.3 & 26.7 & -4.6 & 53.2 & 51.3 & -2.0 \\
Chiapas & 46.2 & 48.6 & 2.4 & 55.1 & 58.0 & 2.9 & 75.1 & 78.1 & 3.0 \\
\hline
\end{tabular}

Fuente: CONEVAL.

Se puede ver que en Chiapas hay más pobres en 2010 que en 1990 en las tres modalidades (alimentaria, capacidades y patrimonio), no es el caso del promedio nacional que disminuye ligeramente. En relación al índice de Gini, también se da el caso que Chiapas es la entidad que exhibe el Gini más desigual del país es dónde menos disminuye (véase gráfica 5).

En la gráfica 9, se observa como la pobreza y la desigualdad de prácticamente todos los municipios de Chiapas se incrementó. El porcentaje máximo de población en pobreza alimentaria alcanzó 81\% a nivel municipal en 1990. Este porcentaje se incrementó a 86\% para el año 2010, lo que implicó que no sólo un mayor número de municipios padecieron los estragos de la pobreza, sino que la misma se presentará con mayor intensidad en una mayor proporción de municipios.

El EZLN se levantó en armas para mejorar las condiciones de vida de los pueblos indígenas, pero hoy hay más pobreza que en 1990, antes del levantamiento zapatista, pese a la transferencia masiva de recursos federales la pobreza en el estado parece estar democratizándose. En la gráfica 10 puede verse que la distribución de la pobreza por municipio, en 1990, mostraba una forma "normal" lo que implica que existían pocos municipios con altos y bajos niveles de pobreza, la mayoría se concentran en el centro de la distribución. Para el año 2010, la distribución de la pobreza municipal parece seguir una distribución uniforme, donde todos los municipios presentan los mismo (altos) niveles de pobreza, una clara señal del fracaso de los programas sociales de corte asistencialista. 
El levantamiento del EZLN visibilizó el problema de la pobreza de Chiapas, vinieron recursos pero éstos no han tenido efectos sobre los que deberían tenerlos: los pobres, entre los que se encuentran la mayoría de los indígenas. Alrededor de 30\% de la población del estado de Chiapas es indígena.

\section{Gráfica 8 \\ Evolución de los indicadores de pobreza y desigualdad en los mu- nicipios de Chiapas, 1990 y 2010}

(a) Pobreza alimentaria municipal, Chiapas

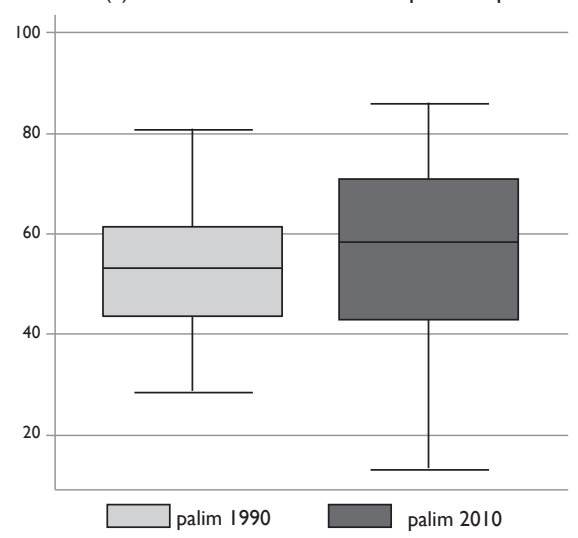

(b) Índice de Gini municipal, Chiapas

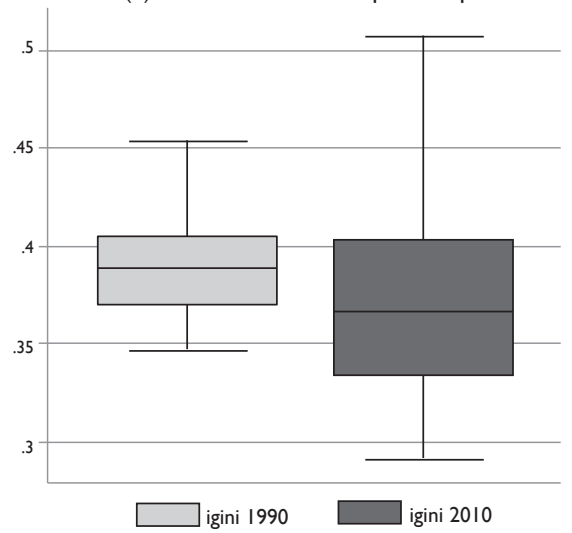

Fuente: elaboración propia con base en datos de CONEVAL.

Con base en lo anterior se puede decir, que en Chiapas el gasto gubernamental ha servido como maximizador de utilidad de los burócratas y las élites políticas, que les ha permitido obtener mayor poder y prestigio en sus cargos, pues son quienes han tenido la posibilidad de expandir el tamaño de la burocracia a expensas de la eficiencia (Rodríguez y López, 2014). De acuerdo a Meltzer y Richard (1981) y Persson y Tabellini (1990) consideran motivos de elección pública: suponiendo que la acción gubernamental tiene un elemento de redistribución, ellos explican que el aumento del gasto eleva el número de votantes de bajo ingreso, quienes presionan para obtener un ingreso mayor y más redistributivo (citado por Rodríguez y López, 2014).

Chiapas se ha convertido en una economía que se mantiene a flote por las transferencias y aportaciones federales, pero éstas deberían de destinarse a reconvertir la base productiva de la entidad y no despilfarrarse en gasto corriente, lo cual se puede observar en el capítulo de servicios personales del 
gasto público de Chiapas, canales de la corrupción o proyectos fracasados ${ }^{5}$ (López y Mayo, 2012).

En Chiapas podemos constatar que el gasto social que ejerce el gobierno no ha aumentado la renta, que de acuerdo al multiplicador keynesiano, gastarían parte del dinero, en una larga cadena que tendría como consecuencia la activación de la economía. No es que la evidencia empírica no dé la razón a esta hipótesis, ya que se ha aumentado el gasto, pero no se ha producido dicho efecto multiplicador. Un análisis más riguroso debe incluir una revisión exhaustiva de las relaciones entre las variables que impiden que el gasto público se convierta en un detonante económico en el caso concreto de Chiapas y no que la hipótesis keynesiana sea incorrecta.

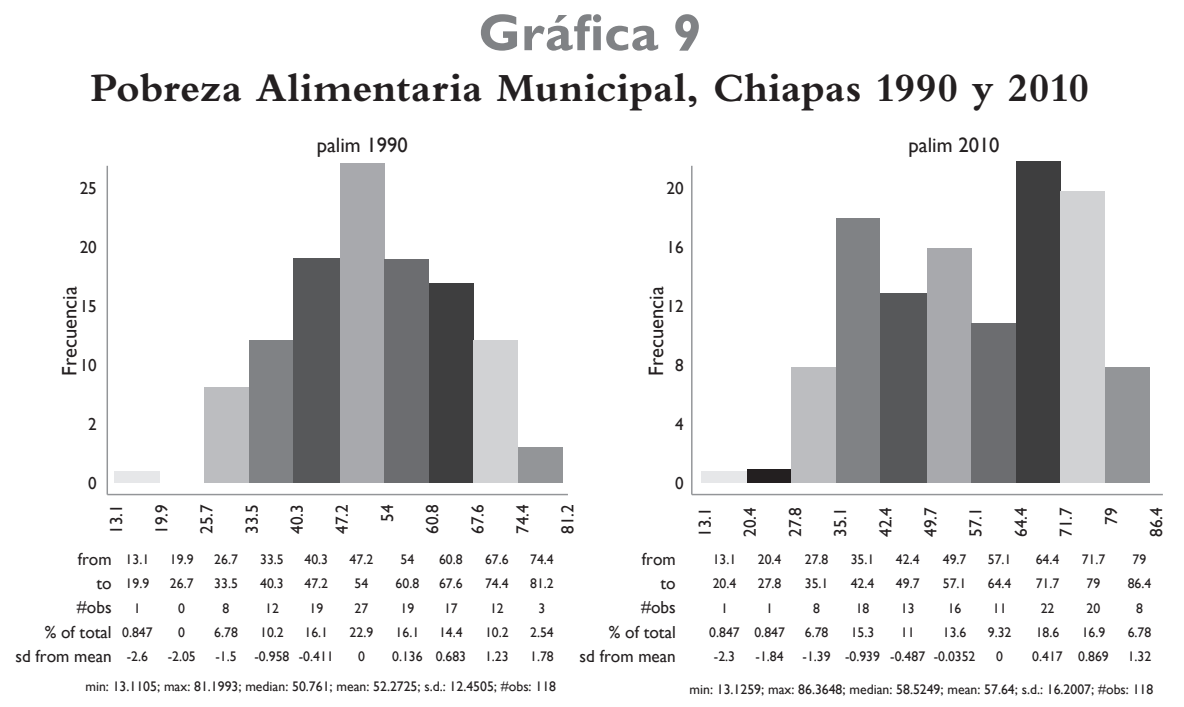

En la gráfica 9 se muestran los niveles medios y la dispersión de la pobreza reportada para los municipios de Chiapas en los años 1990 y 2010. Los niveles de pobreza municipal no sólo parecen no haber disminuido, sino que la pobreza se ha intensificado en algunos municipios y se ha esparcido a un mayor número de los mismos. Es fácil observar que la variabilidad en los niveles de pobreza entre municipios ha crecido de manera importante durante el periodo señalado.

\footnotetext{
${ }^{5}$ Tuxtla Gutiérrez la capital tiene 3 aeropuertos, sólo funciona uno, San Cristóbal de Las Casas y Comitán tienen otros aeropuertos que no funcionan y se le sumará el de Palenque. Los proyectos de bioenergéticos y las ciudades rurales, por mencionar solo algunos.
} 
La desigualdad de ingresos medida en términos del índice de Gini, cuyo comportamiento puede verse en la gráfica 9 , parece seguir el mismo comportamiento de la pobreza, es decir, mayor pobreza y desigualdad en un número creciente de municipios. La evolución de la pobreza alimentaria en los municipios de Chiapas muestra como los esfuerzos de las políticas sociales no han tenido mayor impacto en la reducción de la pobreza. Es importante señal que la pobreza alimentaria está presente en todos los municipios del estado con porcentajes superiores a $10 \%$ de la población total del municipio y más aún, entre los años 1990 a 2010 la pobreza alimentaria se incrementó en una importante proporción de municipios, en 1990 solo tres municipios mostraban niveles superiores a 75\% de pobreza alimentaria, para el año 2010 la cifra se pasó a 16 municipios.

\section{Gráfica 10}

\section{Pobreza alimentaria municipal por grado de marginación 1990 y} 2010

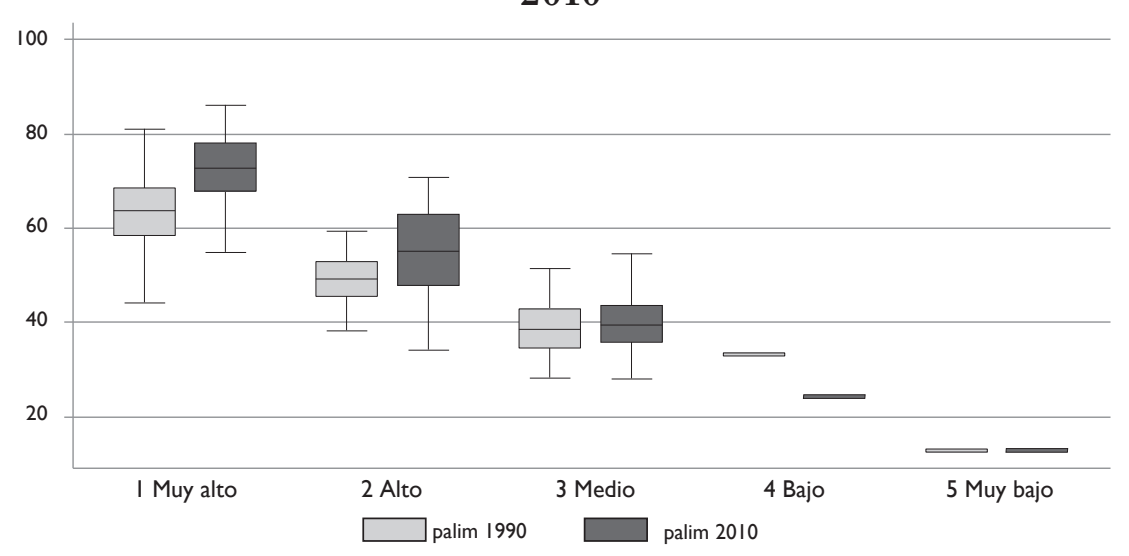

Fuente: elaboración propia con datos de CONEVAL y CONAPO.

Al año 2010, Chiapas contaba con 118 municipios, de los cuales el 98\% presentaba un nivel de marginación muy alto (48), alto (39) y medio (29), solo dos municipios presentaban un nivel de marginación bajo (Reforma) y muy bajo (Tuxtla Gutiérrez). La gráfica 11 muestra que sólo en el municipio de Reforma la pobreza alimentaria disminuyó en el periodo comprendido entre 1990 a 2010, en los restantes municipios la pobreza, según grado de marginación, se incrementó. Los niveles de pobreza alimentaria crecieron de forma más dramática en los municipios con mayores niveles de marginación, es decir, en la mayor parte de los municipios del estado, a saber en 87 de los 118 
municipios. Lo que implica que la pobreza alimentaria, a la par de la marginación, cubren poco más de tres cuartas partes del territorio del estado. Lo que implica que la pobreza se ha democratizado no solo entre los individuos sino también entre los municipios y que abarca cada día una mayor proporción del territorio chiapaneco.

\section{Conclusiones}

Si bien el levantamiento zapatista puso de manifiesto las debilidades del modelo de acumulación chiapaneco y visibilizó la pobreza extrema que vive una parte importante de la población, parecía representar una oportunidad de mejorar las cosas para los excluidos de siempre, pues el gobierno federal volvió los ojos a Chiapas y envío recursos en cantidades significativas como parte de la política de contrainsurgencia. Sin embargo, la gestión de éstos ha dado al traste con cualquier esperanza y nos ha devuelto a una dramática realidad: los pobres hoy son más que en la época de la revuelta y las élites de la juniorcracia ${ }^{6}$ han tomado el poder por asalto e impuesto sus condiciones e intereses. Han demostrado ser más depredadores que sus antecesores y mucho más frívolos, aprovechado para promover una amplia y profunda reestructuración de la forma de hacer política y dirigir la economía: conversión en mercado del voto ciudadano, recomposición de las áreas públicas de negocio en beneficio privado, en inversiones financieras y no financieras, profunda alteración de los equilibrios de poder en provecho de las oligarquías, masiva confiscación de la renta pública que ha permitido el enriquecimiento de unos pocos y profunda deriva democrática. La democracia parece reñida con la pobreza, a mayor pobreza, democracia de menor intensidad, el voto se compra.

En Chiapas se ha desarrollado una cultura rentista en todos los niveles. El político de las élites o los arribistas piensan ocupar cargos para apropiarse de la renta pública por medio de la corrupción, con sus honrosas excepciones. La población empobrecida, y sin opción de encontrar empleo porque la economía no crece, busca obtener rentas de donde sea, de cualquier fuente de renta y da lugar a conflictos intermitentes, de la misma forma ocurre con los programas asistencialistas. Buscan de cualquier manera cumplir con los requisitos impuestos en las reglas de operación de dichos programas y terminan por ser ${ }^{6}$ En Chiapas las élites políticas son parte de la llamada "familia chiapaneca" y descienden en línea recta de exgobernadores, en buena medida. El gobernador Manuel Velasco Coello, nieto del Dr. Manuel Velasco Suárez, exgobernador ya fallecido. Juan Sabines Guerrero, hijo del exgobernador Juan Sabines Gutiérrez, ya fallecido; los senadores actuales, son hijos de exgobernadores y así sucesivamente. 
canjeados como prebendas en la compra-venta del voto. Los recursos públicos han servido para comprar conciencias y lealtades con base en corruptelas, más que para impulsar el desarrollo del estado.

En 16 años de políticas sociales, la pobreza en Chiapas no ha disminuido, más bien, los programas sociales han contribuido a su democratización, ya que si antes existía una distribución normal en los municipios, hoy la pobreza se ha intensificado en algunos municipios y se ha esparcido a un mayor número de los mismos. La política social no remedia los problemas estructurales de la economía en Chiapas y el gobierno debe verlas como complementos, no como sustitutos (Martínez y Peláez, 2014).

Las élites chiapanecas que se benefician con las políticas asistencialistas no tienen ningún tipo de incentivo en propiciar cambios, ya que mientras más pobres existan y sigan fluyendo los recursos fiscales del centro, mejor para ellos, se pueden apropiar de mayor renta pública y les permite fortalecer la relación clientelar con los pobres, ya que el gasto social pasa a operar como una limosna pública, que no crea actividades y trabajos productivos (Valenzuela, 2013), pero si pobres agradecidos que responderán con votos, afianzando la dominación de las élites políticas chiapanecas. Es por ello que los programas sociales no han tenido la utilidad que se plantea en sus actividades programáticas, sino que únicamente han contribuido a democratizar la pobreza en Chiapas.

\section{Bibliografía}

Borts, George H. y Jerome L. Stein (1964), Economic growth in a free market, Columbia University Prees, Nueva York.

Collier, Paul (2007), El club de la miseria: qué falla en los países más pobres del mundo, Turner, Madrid.

Escobar Héctor, Bruno Sovilla y Jorge López Arévalo, "Pobreza, desastres naturales y migración en la regiones Istmo-Costa, Sierra y Soconusco de Chiapas", en Observatorio de la Economía Latinoamericana, núm. 70, noviembre de 2006, en $<$ http://www.eumed.net/cursecon/ecolat/index.htm>.

Guijarro, Marta y Óscar Peláez (2008), “La longevidad globalizada: un análisis de la esperanza de vida en España (1900-2050)”, Scripta Nova, vol. XII, núm. 260, $<$ www.ub.es/geocrit/sn/sn-260.htm>.

Lopez, Jorge y Baltazar Mayo (2012), "Chiapas, endeudamiento en la encrucijada", Economía Informa, Septiembre-Octubre 2012, núm. 376, Universidad Nacional Autónoma de México. 
Economía Informa núm. 393 julio - agosto • 2015

Martínez Julieta y Óscar Peláez (2014), "Políticas asistenciales para rezagos estructurales: el caso de Chiapas", Estudios críticos del Desarrollo, vol. 4, Universidad Autónoma de Zacatecas, Zacatecas, México.

Meltzer, A.H. y S.F. Richard (1981), "A Rational Theory of the Size of Government”, en Journal of Political Economy, 89, pp. 914-927.

Nájera, Jéssica N. y Jorge A. López (2012), “Migración de chiapanecos a los Estados Unidos de América, una visión desde la Encuesta sobre Migración en la Frontera Norte de México, EMIF-NORTE”, en Berumen Salvador y Jorge López Arévalo (Coordinadores), Pobreza y Migración. Enfoques y evidencias a partir de los estudios regionales en México, Editorial Tilde-INM, México, D.F.

Palma, J.G. (2011), 'Homogeneous middles vs. heterogeneous tails, and the end of the 'Inverted-U': The share of the rich is what it's all about', Cambridge Working Papers in Economics 1111, Cambridge: University of Cambridge Department of Economics (later published in Development and Change, 42, 1, 87-153).

Peláez, Óscar (2009), "Descripción y proyección de la esperanza de vida al nacimiento en México (1900-2050)”, Estudios Demográficos y Urbanos, vol. 24, núm. 2 (71), pp. 469-492.

Peláez, Óscar y Jorge López A (2013), “Desigualdades regionales: fuerzas determinantes", en Jorge Isaac Egurrola, Jorge López A. y Luis Quintana (Coordinadores), Desigualdad y desarrollo regional: Chiapas y el Sur Pacífico Mexicano, Plaza y Valdés Editores-Universidad.

Peláez, Óscar (2013), Documento de trabajo sobre economía de Chiapas, El Colegio de la Frontera Norte, no publicado.

Peláez, Óscar, Marta Guijarro y Mercedes Arias (2010), "A state-level analysis of life expectancy in Mexico (1990-2006)", Journal of Biosocial Science, vol. 42, núm. 6.

Persson, T. y G. Tabellini (1990), Macroeconomic Policy, Credebility and Politics, Londres, Harwood Academic.

Rodríguez Benavides, Domingo y Francisco López Herrera (2014), “Desarrollo económico y gasto público de las entidades federativas de México. Análisis de cointegración en panel y la ley de Wagner", Gestión y política pública, Volumen XxiII, Número 2, CIDE; segundo semestre de 2014, México, D. F.

Sachs, Jeffrey (2005), El fin de la pobreza: como conseguirlo en nuestro tiempo, editorial Debate, Madrid, España.

Salama, Pierre (2008), El desafío de las desigualdades. América Latina/Asia: Una comparación económica, Siglo XXI editores, México, D.F.

Valenzuela Feijóo, José (2013), “Un mundo ancho y más ajeno: neoliberalismo y desigualdades regionales", Desigualdad y desarrollo regional: Chiapas y el Sur Pacífico Mexicano, Plaza y Valdés editores. 
Villafuerte, Daniel (2010), "Condiciones de vulnerabilidad productiva, económica y social”, en D. Villafuerte y E. Mansilla coordinadores, Vulnerabilidad y riesgos en la Sierra de Chiapas: dimensiones económica y social, pág. 95; UNICACH, Tuxtla Gutiérrez, Chiapas.

\section{Bases de datos consultadas}

Conapo, Indicadores Demográficos Básicos 1990-2030, de CONAPO

$<$ http://www.portal.conapo.gob.mx/index.php?option=com_content\&view $=$ arti cle $\&$ id=125\&Itemid=230 $>$ [Consultada el 2-3 de diciembre de 2013].

Coneval, Anexo estadístico de pobreza en México. Resultados de pobreza en México a nivel nacional y por entidad federativa 2010-2012, <http://www.coneval.gob.mx/Medicion/Paginas/Medici\%C3\%B3n/Pobreza\%202012/Anexoestad\%C3\%ADstico-pobreza-2012.aspx> [Consultada el 2-3 de diciembre de 2013].

Encuesta Nacional de Ocupación y Empleo (ENOE):

<http://www.empleo.gob.mx/wb/BANEM/BANE_enoe_trim> [Fecha de consulta: 24 de octubre de 2013]

INEGI, Banco de Información Económica. < http://www.inegi.org.mx/sistemas/ bie/> [Consultada del 2 al 5 de diciembre de 2013].

Instituto Nacional para el Federalismo y Desarrollo Municipal http://www.inafed. gob.mx/es/inafed/Sistemas_de_Informacion [Consultada 19/10/20147].

Secretaría de Hacienda del Gobierno del Estado de Chiapas <http://www.haciendachiapas.gob.mx/rendicion-ctas/informe-finanzas-pub/informacion-financiera/consolidada/2-proyecto.asp> [Consultada el 07/10/2014]. 